\title{
Overall survival in response to sorafenib versus radiotherapy in unresectable hepatocellular carcinoma with major portal vein tumor thrombosis: propensity score analysis
}

\author{
Takahide Nakazawa ${ }^{1,2^{*}}$, Hisashi Hidaka', Akitaka Shibuya', Yusuke Okuwaki', Yoshiaki Tanaka', Juichi Takada',
} Tsutomu Minamino ${ }^{1}$, Masaaki Watanabe' ${ }^{1}$ Shigehiro Kokubu ${ }^{3}$ and Wasaburo Koizumi ${ }^{1}$

\begin{abstract}
Background: This study investigated the survival benefits of sorafenib vs. radiotherapy (RT) in patients with unresectable hepatocellular carcinoma (HCC) and portal vein tumor thrombosis (PVIT) in the main trunk or the first branch.

Methods: Ninety-seven patients were retrospectively reviewed. Forty patients were enrolled by the Kanagawa Liver Study Group and received sorafenib, and 57 consecutive patients received RT in our hospital. Overall survival was compared between the two groups with PVTT by propensity score (PS) analysis. Factors associated with survival were evaluated by multivariate analysis.

Results: The median treatment period with sorafenib was 45 days, while the median total radiation dose was $50 \mathrm{~Gy}$. The Child-Pugh class and the level of invasion into hepatic large vessels were significantly more advanced in the RT group than in the sorafenib group. Median survival did not differ significantly between the sorafenib group (4.3 months) and the RT group (5.9 months; $P=0.115)$. After PS matching ( $n=28$ per group), better survival was noted in the RT group than in the sorafenib group (median survival, 10.9 vs. 4.8 months; $P=0.025$ ). A Cox model showed that des- $\gamma$-carboxy prothrombin $<1000 \mathrm{mAU} / \mathrm{mL}$ at enrollment and RT were significant independent predictors of survival in the PS model $(P=0.024, \mathrm{HR}, 0.508 ; 95 \% \mathrm{Cl}, 0.282$ to 0.915 ; and $P=0.007, \mathrm{HR}, 0.434 ; 95 \%$ $\mathrm{Cl}, 0.235$ to 0.779 ; respectively).
\end{abstract}

Conclusions: RT is a better first-line therapy than sorafenib in patients who have advanced unresectable HCC with PVIT.

Keywords: Hepatocellular carcinoma, Overall survival, Portal venous tumor thrombosis, Radiotherapy, Sorafenib

\section{Background}

Hepatocellular carcinoma (HCC) recurs frequently after curative treatment [1-4]. Advanced HCC sometimes causes macroscopic hepatic vascular invasion, including portal vein tumor thrombosis (PVTT) in the main portal trunk or the first branch and venous thrombosis in the hepatic vein trunk or inferior vena cava. These conditions can

\footnotetext{
* Correspondence: tnakazaw@kitasato-u.ac.jp

'Department of Gastroenterology, Internal Medicine, Kitasato University

School of Medicine, 2-1-1 Asamizodai, Minami-ku, Sagamihara, Kanagawa 252-0380, Japan

${ }^{2}$ Nakazawa Medical Clinic, Sagamihara, Japan

Full list of author information is available at the end of the article
}

be life threatening, and the prognosis of patients with PVTT remains very poor, with a median survival of only approximately 3 months without treatment [5-8]. Therefore, identification of effective treatments that are not associated with significant adverse effects would be of benefit for this patient population. Transarterial chemoembolization (TACE) is one treatment for advanced HCC and is associated with an increased risk of ischemic necrosis of the liver and of treatment-related death in patients with PVTT. Therefore, this strategy is limited to a select group of patients with good hepatic function, patients with PVTT other than in the main or the first branch, and those with 
adequate collateral circulation around the occluded portal vein. Other treatment options include hepatic infusion chemotherapy mainly with 5-fluorouracil and cisplatin with or without interferon [9-11]. However, the efficacy of such treatments is limited, and this regimen can cause considerable stress for patients.

The use of molecular targeted therapy continues to increase. Sorafenib is an oral multikinase inhibitor with antiangiogenic and antiproliferative effects that significantly improves time-to-tumor progression and overall survival (OS) of patients with advanced HCC and is widely used to treat advanced HCC in which curative therapy is not indicated [12-14]. Sorafenib inhibits several tyrosine kinase receptors, including vascular endothelial growth factor (VEGF) receptor (R)-2, VEGFR-3, platelet-derived growth factor receptor $\beta$, FLT-3, and C-kit [15]. Although the use of sorafenib is limited to a select group of patients with good hepatic function, it can also be effective for patients with advanced HCC and a poor prognosis, including those with worse ECOG performance status, extrahepatic spread, vascular invasion, older age, and presence of macroscopic vascular invasion or extrahepatic spread [12]. However, care must be exercised due to the fact that sorafenib frequently causes various adverse events (AEs) such as hand-foot syndrome, gastrointestinal hemorrhage, and use-limiting anorexia [12-14].

Radiotherapy (RT) can produce survival benefits in patients with advanced HCC and macroscopic hepatic vascular invasion [7,16-18]. We previously reported that the use of three-dimensional conformal RT (3D-CRT) resulted in a good disease control rate and prolonged survival in these patients. Because of a high induction rate of stable disease (SD), both responders and nonresponders had improved outcomes when compared with patients who received supportive care alone [8,17]. Another advantage of 3D-CRT is that treatment can be administered on an outpatient basis without the difficulties associated with TACE or hepatic infusion chemotherapy, and RT did not produce grade 3 or higher liver, gastrointestinal, or hematological toxicity $[8,17]$.

The goal of the present study was to compare the survival benefit of sorafenib versus RT in two retrospective cohorts of patients with advanced HCC and PVTT in the main trunk or the first branch. Propensity score analysis was used to reduce biases, and potential predictors of survival were analyzed using a Cox model.

\section{Methods}

\section{Study population}

Ninety-seven patients with macroscopic hepatic vascular invasion were retrospectively reviewed following approval by the institutional review board at Kitasato University East Hospital. Study protocols were conducted in accordance with the principles of the Declaration of Helsinki. All patients provided written, informed consent. HCC with macroscopic hepatic vascular invasion included patients with portal tumor invasion involving first-order branches and the main trunk of the portal vein, and venous thrombosis in the hepatic vein trunk or inferior vena cava. A diagnosis of tumor invasion and macroscopic hepatic vascular invasion was established in all patients by computed tomography (CT) on the basis of the following criteria: (i) a low-attenuation intraluminal filling defect with expanded macroscopic hepatic vascular invasion adjacent to the primary tumor during the portal phase, and (ii) an enhanced inner side of the filling defect during the arterial phase. Forty patients treated with sorafenib enrolled in the Kanagawa Liver Study Group (four institutes in Kanagawa Prefecture in Japan) and 57 consecutive HCC patients treated with RT in Kitasato University East Hospital (Sagamihara, Kanagawa, Japan) were examined. Overall survival (OS) and AEs were compared between the two groups of the entire cohort and in a PS-matched cohort. Factors potentially associated with OS were analyzed statistically in a PSmatched model. Treatment response was not compared, because the Response Evaluation Criteria in Solid Tumors (RECIST) criteria (version 1.1) and the modified RECIST criteria, which are commonly used for patients with HCC treated with sorafenib, were not adapted for use in patients with macroscopic hepatic vascular invasion $[19,20]$. The follow-up period was from initiation of treatment to the time of death. AEs were assessed according to the National Cancer Institute Common Terminology Criteria for Adverse Events, version 4.0.

\section{Sorafenib group}

From July 2009 through November 2011, a total of 40 patients with advanced HCC with macroscopic hepatic vascular invasion and chronic liver disease of mainly Child-Pugh (C-P) class A received sorafenib at four institutes in Kanagawa Prefecture in Japan (Kitasato University East Hospital, Sagamihara; Yokohama City University Hospital, Yokohama; St. Marianna University Hospital, Kawasaki, and Kanagawa Cancer Center, Yokohama). Eligibility criteria for treatment with sorafenib were as follows: (i) unresectable advanced HCC without HCC rupture; (ii) no effect of TACE; (iii) no previous sorafenib therapy for the liver tumor; (iv) C-P class A or B (up to a score of 7 points) hepatic function; (v) an Eastern Cooperative Oncology Group (ECOG) performance status of $0-2$ [21]; and (vi) the following laboratory findings: neutrophil count above $1500 / \mu \mathrm{L}$, platelet count above $7.5 \times$ $10^{4} \mathrm{~mm}^{3}$, and serum hemoglobin level above $8.5 \mathrm{~g} / \mathrm{dL}$. Patients initially received a standard dose of sorafenib, $400 \mathrm{mg}$ twice daily (800 mg/day) or $200 \mathrm{mg}$ twice daily (400 mg/day) for those with low body weight. The dose 
was reduced or treatment was temporarily suspended in patients who had drug-related grade 2-4 toxicities (until recovery to grade 1 or less) or at the discretion of the treating physician. The initial reduced dose of sorafenib was $400 \mathrm{mg} /$ day. The dose was increased to the standard dose level in accordance with each patient's tolerance. Treatment was continued until radiologic progression or recurrence of $\mathrm{HCC}$, unacceptable toxicity associated with the study drug, or withdrawal of consent.

\section{RT group}

From July 2001 through November 2011, 57 consecutive patients with advanced HCC and macroscopic hepatic vascular invasion initially received 3D-CRT at Kitasato University East Hospital, Sagamihara, Japan. Inclusion criteria for patients who received RT were as follows: (i) unresectable $\mathrm{HCC}$ with macroscopic hepatic vascular invasion; (ii) $\mathrm{C}$-P class $\mathrm{A}$ or $\mathrm{B}$ hepatic function; (iii) an ECOG performance status of $0-2$; (iv) no refractory ascites; and (v) no previous radiation therapy of the liver. The RT procedure was performed as described previously $[8,17]$. Briefly, macroscopic hepatic vascular invasion was mainly irradiated, regardless of the presence or absence of multinodular HCC. RT doses and treatment angles were determined with the use of a 3D-view technique to minimize critical organ injury. CT planning was used to determine radiation fields and the clinical target volume (CTV), which was defined as only the macroscopic hepatic vascular invasion. The main HCC was also irradiated together with hepatic vascular invasion if the tumor was directly involved. Other multiple nodules were not always included in the CTV. 3D-CRT was planned according to tentative guidelines to ensure that the normal liver volume irradiated with more than one half of the prescribed dose did not exceed $50 \%$ of the total liver volume. A daily radiation dose of 1.8 to 2.0 Gy was administered with a 6- or 10-MV X-rays using two- to four-port combinations. Five fractions were administered per week to deliver a total dose of around $50 \mathrm{~Gy}$.

\section{Statistical analysis}

The overall survival rates of patients who underwent sorafenib or RT were calculated from the date of diagnosis of macroscopic hepatic vascular invasion. The primary end point was all-cause mortality. The Chi-square or Fisher's exact test was used to compare categorical variables, whereas Student's $t$-test or the Mann-Whitney $U$ test was used for continuous variables. The Kaplan-Meier method was used to obtain the cumulative survival rate. PS analysis was performed using multiple logistic regression to analyze patients treated with sorafenib or RT. Variables associated with treatment decisions were entered in the PS model. The PS model was then used to provide a one-toone match between the sorafenib and RT groups by the nearest-neighbor matched method [22]. In each matched subgroup, survival curves were compared using the logrank test. Variables that achieved significance $(P<0.05)$ or those that were close to significance $(P<0.15)$ by the logrank test were subsequently included in the multivariate analysis using a forward stepwise Cox regression model for the analysis of factors associated with OS, with adjustments for confounding factors. A two-tailed $P<0.05$ was considered significant. All statistical analyses were performed (a)

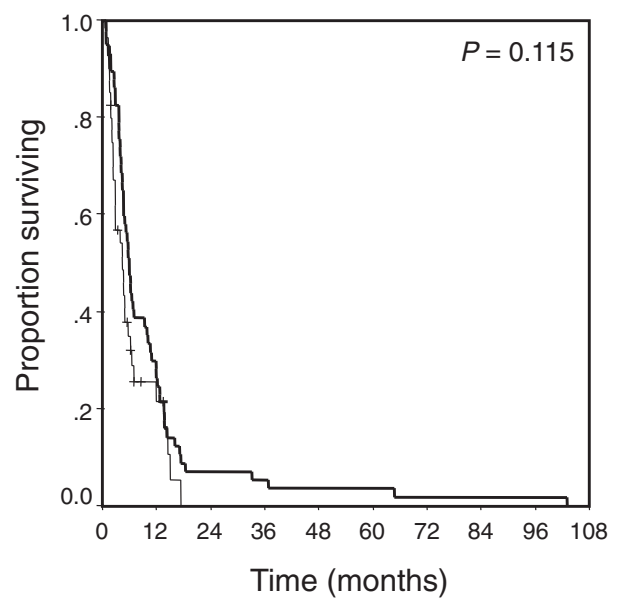

(b)

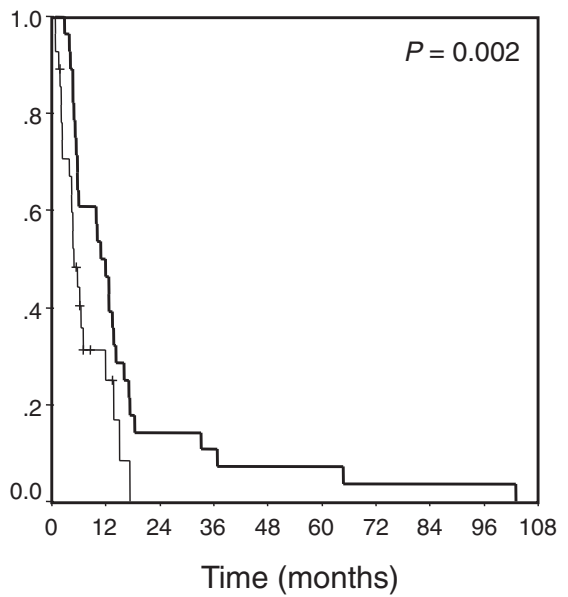

Figure 1 Kaplan-Meier curves for OS of the RT (bold lines) and sorafenib (solid lines) groups. (a), all patients ( $n=97)$ and (b), PS-matched patients $(n=56)$. Although no significant difference between the two groups is observed in $(\mathbf{a})(P=0.115)$, OS in the PS-matched patients is significantly longer in the RT group (median 10.9 months) than in the sorafenib group (median 4.8 months), as shown in (b) $(P=0.002$, log-rank test). 
Table 1 Baseline characteristics of 64 patients with Child-Pugh class A and 56 patients matched by propensity score

\begin{tabular}{|c|c|c|c|c|c|c|}
\hline \multirow[b]{3}{*}{ Covariates } & \multicolumn{3}{|c|}{ Entire cohort } & \multicolumn{3}{|c|}{ PS-matched cohort } \\
\hline & Sorafenib & RT & $P$ value & Sorafenib & RT & $P$ value \\
\hline & $\mathrm{n}=36$ & $\mathrm{n}=\mathbf{2 8}$ & & $\mathrm{n}=\mathbf{2 8}$ & $\mathrm{n}=\mathbf{2 8}$ & \\
\hline Age (years) & $70(62-78)$ & $67(61-71)$ & 0.069 & $70(61-78)$ & $67(61-70)$ & 0.04 \\
\hline Sex (male/female) & $31 / 5$ & $19 / 9$ & 0.127 & $23 / 5$ & $19 / 9$ & 0.355 \\
\hline $\mathrm{HCV}$ & $19 / 17$ & $17 / 11$ & 0.615 & $16 / 12$ & $17 / 11$ & 1.0 \\
\hline *Main/first branch & $7 / 29$ & $9 / 19$ & 0.262 & $7 / 24$ & $9 / 19$ & 0.205 \\
\hline Metastases (present/absent) & $7 / 29$ & $2 / 26$ & 0.278 & $6 / 22$ & $2 / 26$ & 0.252 \\
\hline Previous Treatments (present/absent) & $26 / 10$ & 20/8 & 1.0 & $18 / 10$ & 20/8 & 0.775 \\
\hline TACE/TAl & 21 & 20 & & 15 & 20 & \\
\hline RFA & 3 & 0 & & 2 & 0 & \\
\hline RT & 2 & 0 & & 1 & 0 & \\
\hline AFP (ng/dL) & $1047(44-5919)$ & $43(10-1096)$ & 0.005 & $680(37-3708)$ & $43(10-1096)$ & 0.144 \\
\hline $\mathrm{DCP}(\mathrm{mAU} / \mathrm{mL})$ & 2915 (111-19706) & $224(33-2880)$ & 0.013 & $2151(58-10775)$ & $224(33-2880)$ & 0.488 \\
\hline
\end{tabular}

Data are presented as medians (range).

Abbreviations: TACE transarterial chemoembolization, TAl transarterial infusion chemotherapy, $R F A$ radiofrequency ablation, $R T$ radiotherapy, $H C V$ hepatitis $C$ virus, $A F P$ a-fetoprotein, $D C P$ des- $\gamma$-carboxy prothrombin, AST aspartate aminotransferase, $A L T$ alanine aminotransferase, $P S$ propensity score.

*Portal tumor invasion to the main trunk or first branch.

using the Statistical Package for Social Sciences (SPSS 17.0 for Windows, SPSS, Inc. Chicago, IL).

\section{Results}

\section{Patient characteristics and crude OS in response to} sorafenib versus $\mathrm{RT}$

All patients $(n=97)$ underwent either sorafenib $(n=40)$ or RT $(\mathrm{n}=57)$ treatment. In the sorafenib group, 28 patients initially received a dose $400 \mathrm{mg}$ of sorafenib twice daily (800 mg/day), while 12 received a dose of $200 \mathrm{mg}$ of sorafenib twice daily ( $400 \mathrm{mg} /$ day) because of older age, low body mass index, or anorexia. The mean duration of treatment with sorafenib was 45 days (range, 7-400 days).

A total radiation dose of 30 to $56 \mathrm{~Gy}$ (median $50 \mathrm{~Gy}$ ) was delivered, and a combination of PVTT and hepatic vein tumor thrombosis (HVTT) was observed in 10 patients in the RT group. The sorafenib group had significantly better hepatic function of C-P class A/B (sorafenib 36/4 and RT $34 / 23$ patients, respectively, $P=0.001$ ) and median platelet counts than the RT group (sorafenib 15.1 and RT $11.8 \times 10^{4} / \mathrm{mm}^{3}$, respectively, $P=0.004$ ). Tumor thrombosis in the main portal trunk was significantly more common in the RT group than in the sorafenib group (main/first branch: sorafenib 7/33 and RT 22/35 patients, respectively, $P=0.021)$. Otherwise, age, sex, the proportions of antihepatitis $C$ virus-positive and of extrahepatic spread, and the median values of laboratory findings including $\alpha$ fetoprotein and des- $\gamma$-carboxy prothrombin were not significantly different between the two groups. Thirty-three patients treated with sorafenib died (83\%), while 57 treated with RT died during the observation period. Despite the fact that the RT study population had significant worsening of hepatic function and tumor progression in comparison with the sorafenib group, crude OS was not significantly different between the two groups $[P=0.115,4.4$ months (range, 0.7-17.5) in the sorafenib group, and 5.9 months (range, 0.6-103) in the RT group], as shown in Figure 1a.

\section{OS and factors related to OS in the PS-matched population}

A total of 64 patients with C-P class A hepatic function and PVTT only. (sorafenib; $\mathrm{n}=36, \mathrm{RT} ; \mathrm{n}=28$ ) was extracted for PS analyses, as shown in Table 1 and Figure 2. Six of the 34 RT group patients with C-P class A were excluded because they had a combination of PVTT and HVTT. Significant differences between these two groups were observed in baseline levels of the tumor markers $\alpha$ fetoprotein and des- $\gamma$-carboxy prothrombin (DCP). PS analysis with the one-to-one nearest-neighbor matching

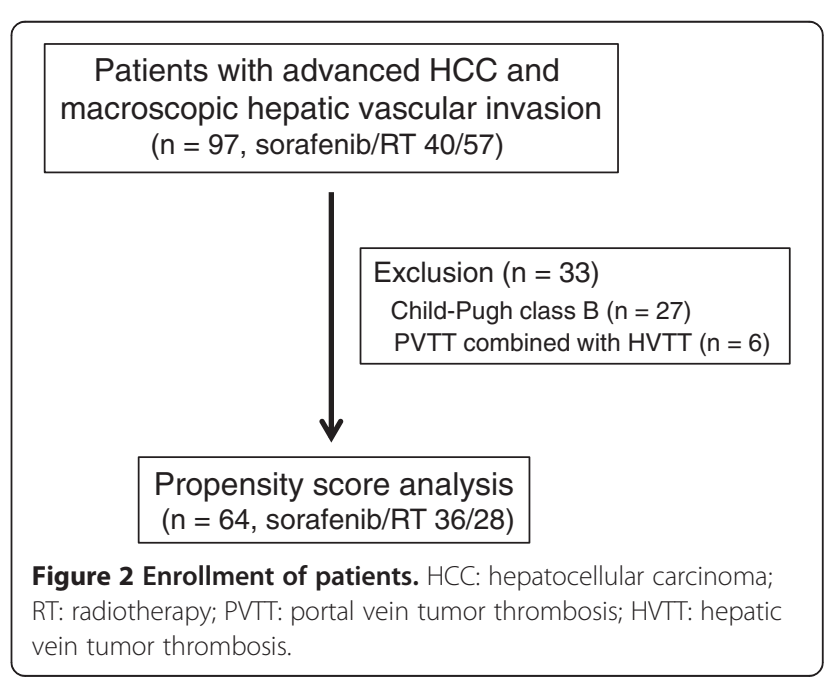


Table 2 Cox regression analysis of factors potentially related to overall survival

\begin{tabular}{|c|c|c|c|c|c|}
\hline \multirow[b]{2}{*}{ Covariates } & \multicolumn{2}{|c|}{ Log-rank test } & \multicolumn{3}{|c|}{ Cox } \\
\hline & $\mathrm{n}$ & $P$ value & $P$ value & HR & $95 \% \mathrm{Cl}$ \\
\hline Age $(\geq 70 /<70 y)$ & $33 / 23$ & 0.355 & & & \\
\hline Sex (male/female) & $42 / 14$ & 0.424 & & & \\
\hline HCV (present/absent) & $34 / 22$ & 0.58 & & & \\
\hline *Main trunk (present/absent) & $16 / 40$ & 0.612 & & & \\
\hline Extrahepatic spread (present/absent) & $5 / 51$ & 0.278 & & & \\
\hline Previous treatments (present/absent) & $38 / 18$ & 0.546 & & & \\
\hline AFP $\geq 100$ (ng/dL) & $28 / 28$ & 0.073 & & & \\
\hline $\mathrm{DCP} \geq 1000(\mathrm{mAU} / \mathrm{mL})$ & 27 & 0.066 & 0.024 & 1 & \\
\hline$<1000$ & 29 & & & 0.508 & $0.282,0.915$ \\
\hline Sorafenib & 28 & 0.002 & 0.007 & 1 & \\
\hline RT & 28 & & & 0.434 & $0.235,0.779$ \\
\hline
\end{tabular}

Abbreviations: $H C V$ hepatitis $C$ virus, AFP a-fetoprotein, $D C P$ des- $\gamma$-carboxy prothrombin, $R T$ radiotherapy, $H R$ hazard ratio, $C l$ confidence interval.

*Portal invasion to the main trunk.

method was conducted to minimize selection bias and to adjust backgrounds. The two PS-matched groups (28 patients per group) were well balanced, as shown in Table 1. The PS-matched model was validated by the Hosmer and Lemeshow goodness-of-fit test $(P=0.091)$ and by the value of the area under the curve $(0.719 ; 95 \% \mathrm{CI}, 0.594-0.844)$. In the PS-matched cohort, the median OS was significantly shorter in the sorafenib group (4.8 months; range, 0.7-17.3) than in the RT group (10.9 months; range, 2.8-103; $P=$ 0.002 , log-rank test), as shown in Figure 1b. Cox regression analyses showed that DCP $<1000 \mathrm{mAu} / \mathrm{mL}$ at pretreatment and RT were independent contributors to OS $(P=0.024$; HR, 0.508; 95\% CI, 0.282 to $0.915 ; P=0.007$; HR, 0.434; $95 \%$ CI, 0.235 to 0.779 , respectively) (Table 2 ).

\section{Treatment tolerability}

Treatment tolerability was analyzed by comparison of the AEs between the sorafenib and RT groups matched according to PS score. In the sorafenib group, 25 (90\%) of 28 patients permanently discontinued sorafenib (due to AEs, $n=15$; disease progression, $n=10$ ). There was no radiographic or clinical evidence of pancreatitis, and there were no drug-related deaths. As shown in Table 3, AEs of grade 3 or more were observed in 19 patients, and almost all AEs were related to the liver (AST/ALT increase in six patients, anorexia/nausea in four patients, hepatic failure in one patient, and ascites in one patient). In the RT group, there was no grade 3 or higher gastrointestinal or hepatic toxicity, including anorexia/nausea, gastric ulcer, increase in AST/ALT, or hepatic failure. Grade 3 leukocytopenia was observed in only one patient. There were no long-term sequelae.

\section{Discussion}

PS analysis demonstrated that RT was associated with better survival than sorafenib in patients with advanced unresectable HCC and PVTT. PVTT occurs in a substantial portion of $\mathrm{HCC}$ patients and is evident in up to approximately $40 \%$ of HCC patients at the time of death $[7,9,23]$. Sorafenib is an oral multikinase inhibitor that prolongs survival and the time to progression in patients with advanced HCC. This drug is also effective in patients with advanced HCC and poor prognosis, including those with worse ECOG performance status, extrahepatic spread,

Table 3 Comparison of AEs between sorafenib and RT

\begin{tabular}{lcc}
\hline & Sorafenib & RT \\
\hline Grade 3/4 toxicity & 19 & 1 \\
Total (n) & 6 & 0 \\
AST/ALT increased & 4 & 0 \\
Anorexia/nausea & 3 & 0 \\
HFSR & 1 & 0 \\
Hepatic Failure & 1 & 0 \\
Ascites & 1 & 0 \\
Hypertension & 1 & 0 \\
Proteinuria & 1 & 0 \\
Sepsis & 1 & 0 \\
Thrombocytopenia & 0 & 0 \\
Anemia & 0 & 1 \\
Leukocytopenia & 0 & 0 \\
Pancreatitis & $15(54)$ & $1(4)$ \\
Discontinuation, $\mathrm{n}(\%)$ &
\end{tabular}

Abbreviations: AEs adverse events, AST aspartate aminotransferase, ALT alanine aminotransferase, $R T$ radiotherapy, HFSR hand-foot-skin reaction. 
vascular invasion, older age, and the presence of macroscopic vascular invasion or extrahepatic spread [12]. In a recent PS analysis of sorafenib alone versus sorafenib combined with TACE for advanced HCC (in which $20-30 \%$ of the patient population had major trunk PVTT), neither regimen produced a significant benefit in OS [24]. We previously reported that RT produced favorable survival benefits without the hardships associated with conventional treatment for macroscopic hepatic vascular invasion $[8,17]$.

The current study demonstrated that DCP $<1000$ $\mathrm{mAu} / \mathrm{mL}$ at pretreatment and RT were independently related to OS, according to a Cox model in a PS analysis. The serum DCP level correlates with intrahepatic vascular invasion, and the DCP level might reflect expansion of macroscopic hepatic vascular invasion [25]. These findings suggest that the first goal of therapy for advanced HCC with major PVTT should consist of intensive treatment to recanalize the PVTT. RT is more effective than sorafenib, because major PVTT is intensively irradiated by RT. In fact, the overall objective response rate (complete response plus partial response) for PVTT by RT reached $45 \%$, and the response rate was even better in patients with C-P class A [17]. In addition, 3D-CRT for PVTT can minimize liver-related AEs (Table 3). Almost all patients receiving sorafenib discontinued therapy (due to AEs or disease progression), while only one patient discontinued RT. Involvement of the main PVTT is associated with poor prognosis, possibly because of increased risk of tumor spread, elevated portal venous pressure causing variceal hemorrhage, and decreased portal flow resulting in ascites, jaundice, hepatic encephalopathy, and liver failure [7,9,23,26]. Sorafenib can compromise hepatic function by decreasing portal blood flow, as we previously demonstrated that sorafenib induced significant vasoconstriction of the portal venous area and significantly reduced portal venous flow, according to Doppler ultrasonography in patients with unresectable HCC [27]. Other investigators have used magnetic resonance imaging to show similar results [28]. Therefore, we believe that sorafenib should be administered only after recanalization of major PVTT by other treatments [9].

The optimal treatment regimen for patients with unresectable HCC and PVTT remains to be established. C-P class A hepatic function is likely related to the treatment response and survival, because it was previously identified as one of the factors contributing to OS in various treatments for HCC. Furthermore, we previously reported that C-P class A hepatic function was related to the response to RT [17]. Conversely, patients with C-P class B hepatic function tend to have a poor response to treatment, because treatments often further impair hepatic function.

Limitations of the current study include the small study population, as the number of patients with HCC and major PVTT is relatively small in the general population. Furthermore, this was a non-prospectively randomized study, and the evaluation of responsiveness to sorafenib may have been incomplete due to the involvement of different institutions. Therefore, OS and contributing factors were analyzed by PS analysis.

\section{Conclusions}

First-line therapy for unresectable HCC with PVTT should consist of RT rather than sorafenib. Sorafenib should be introduced after recanalization of PVTT by other treatments, including RT. Multidisciplinary therapies based on individual hepatic function are expected to improve outcomes in the future.

\section{Abbreviations}

RT: Radiotherapy; HCC: Hepatocellular carcinoma; PVTT: Portal vein tumor thrombosis; HVTT: Hepatic vein tumor thrombosis; PS: Propensity score; TACE: Transarterial chemoembolization; OS: Overall survival; VEGF: Vascular endothelial growth factor; AE: Adverse event; 3D-CRT: Three-dimensional conformal RT; RECIST: Response Evaluation Criteria in Solid Tumors; C-P: Child-Pugh; ECOG: Eastern Cooperative Oncology Group; CTV: Clinical target volume.

\section{Competing interests}

The authors declare that they have no competing interests.

\section{Authors' contributions}

Conception and design: TN, $H H, Y O, Y T$, and JT; analysis: TN and $Y O$; treatment and data collection: $\mathrm{TN}, \mathrm{HH}, \mathrm{YO}, \mathrm{YT}$, JT, and TM; drafting article: TN and AS; critical revision: MW, SK, and KW. All authors read and approved the final manuscript.

\section{Acknowledgements}

With regard to sorafenib-related data collection, the authors would like to thank the following colleagues of the Kanagawa Liver Study Group: Katsuaki Tanaka, Kazushi Numata, and Masaaki Kondo from the Gastroenterological Center, Yokohama City University Medical Center; Michihiro Suzuki, Chiaki Okuse, and Kotaro Matsunaga from Gastroenterology and Hepatology, Department of Internal Medicine, St Marianna University School of Medicine; and Shinichi Ohkawa, Manabu Morimoto, and Satoshi Kobayashi from Hepatobiliary and Pancreatic Medical Oncology, Kanagawa Cancer Center Hospital.

\section{Author details}

'Department of Gastroenterology, Internal Medicine, Kitasato University School of Medicine, 2-1-1 Asamizodai, Minami-ku, Sagamihara, Kanagawa 252-0380, Japan. ${ }^{2}$ Nakazawa Medical Clinic, Sagamihara, Japan. ${ }^{3}$ Department of Gastroenterology, Juntendo University Nerima Hospital, Tokyo, Japan.

Received: 27 January 2014 Accepted: 29 April 2014

Published: 3 May 2014

\section{References}

1. Poon R, Fan S, Lo C, Wang J: Intrahepatic recurrence after curative resection of hepatocellular carcinoma: long-term results of treatment and prognostic factors. Ann Surg 1999, 229:216-222.

2. Nakazawa T, Kokubu S, Shibuya A, Ono K, Watanabe M, Hidaka H, Tsuchihashi T, Saigenji K: Radiofrequency ablation of hepatocellular carcinoma: correlation between local tumor progression after ablation and ablative margin. Am J Roentgenol 2007, 188:480-488.

3. Okuwaki Y, Nakazawa T, Shibuya A, Ono K, Hidaka H, Watanabe M, Kokubu $\mathrm{S}$, Saigenji K: Intrahepatic distant recurrence after radiofrequency ablation for a single small hepatocellular carcinoma: Risk factors and patterns. J Gastroenterol 2008, 43:71-78.

4. Okuwaki Y, Nakazawa T, Kokubu S, Hidaka H, Tanaka Y, Takada J, Watanabe M, Shibuya A, Minamino T, Saigenji K: Repeat radiofrequency ablation 
provides survival benefit in patients with intrahepatic distant recurrence of hepatocellular carcinoma. Am J Gastroenterol 2009, 104:2747-2753.

5. Llovet JM, Bustamante J, Castells A, Vilana R, Ayuso Mdel C, Sala M, Brú C, Rodés J, Bruix J: Natural history of untreated nonsurgical hepatocellular carcinoma: rationale for the design and evaluation of therapeutic trials. Hepatology 1999, 29:62-67.

6. Schöniger-Hekele M, Müller C, Kutilek M, Oesterreicher C, Ferenci P, Gangl A: Hepatocellular carcinoma in Central Europe: prognostic features and survival. Gut 2001, 48:103-109.

7. Minagawa M, Makuuchi M: Treatment of hepatocellular carcinoma accompanied by portal vein tumor thrombus. World J Gastroenterol 2006, 12:7561-7567.

8. Nakazawa T, Adachi S, Kitano M, Isobe Y, Kokubu S, Hidaka H, Ono K, Okuwaki $Y$, Watanabe M, Shibuya A, Saigenji K: Potential prognostic benefits of radiotherapy as an initial treatment for patients with unresectable advanced hepatocellular carcinoma with invasion to intrahepatic large vessels. Oncology 2007, 73:90-97.

9. Lau WY, Sangro B, Chen PJ, Cheng SQ, Chow P, Lee RC, Leung T, Han KH, Poon RT: Treatment for hepatocellular carcinoma with portal vein tumor thrombosis: the emerging role for radioembolization using yttrium-90. Oncology 2013, 84:311-318.

10. Ando E, Tanaka M, Yamashita F, Kuromatsu R, Yutani S, Fukumori K, Sumie S, Yano Y, Okuda K, Sata M: Hepatic arterial infusion chemotherapy for advanced hepatocellular carcinoma with portal vein tumor thrombosis: analysis of 48 cases. Cancer 2002, 95:588-595.

11. Ota $H$, Nagano $H$, Sakon $M$, Eguchi $H$, Kondo M, Yamamoto $T$, Nakamura M, Damdinsuren B, Wada H, Marubashi S, Miyamoto A, Dono K, Umeshita K, Nakamori S, Wakasa K, Monden M: Treatment of hepatocellular carcinoma with major portal vein thrombosis by combined therapy with subcutaneous interferon-alpha and intra-arterial 5-fluorouracil; role of type 1 interferon receptor expression. Br J Cancer 2005, 93:557-564.

12. Llovet JM, Ricci S, Mazzaferro V, Hilgard P, Gane E, Blanc JF, de Oliveira AC, Santoro A, Raoul JL, Forner A, Schwartz M, Porta C, Zeuzem S, Bolondi L, Greten TF, Galle PR, Seitz JF, Borbath I, Häussinger D, Giannaris T, Shan M, Moscovici M, Voliotis D, Bruix J, SHARP Investigators Study Group: Sorafenib in advanced hepatocellular carcinoma. N Engl J Med 2008, 359:378-390.

13. Cheng AL, Kang YK, Chen Z, Tsao CJ, Qin S, Kim JS, Luo R, Feng J, Ye S, Yang TS, Xu J, Sun Y, Liang H, Liu J, Wang J, Tak WY, Pan H, Burock K, Zou J, Voliotis D, Guan Z: Efficacy and safety of sorafenib in patients in the Asia-Pacific region with advanced hepatocellular carcinoma: a phase III randomised, double-blind, placebo-controlled trial. Lancet Oncol 2009, 10:25-34.

14. Nakazawa T, Hidaka H, Takada J, Okuwaki Y, Tanaka Y, Watanabe M, Shibuya A, Minamino T, Kokubu S, Koizumi W: Early increase in a-fetoprotein for predicting unfavorable clinical outcomes in patients with advanced hepatocellular carcinoma treated with sorafenib. Eur J Gastroenterol Hepatol 2013, 25:683-689.

15. Wilhelm SM, Carter C, Tang L, Wilkie D, McNabola A, Rong H, Chen C, Zhang X, Vincent P, McHugh M, Cao Y, Shujath J, Gawlak S, Eveleigh D, Rowley B, Liu L, Adnane L, Lynch M, Auclair D, Taylor I, Gedrich R, Voznesensky A, Riedl B, Post LE, Bollag G, Trail PA: BAY 43-9006 exhibits broad spectrum oral antitumor activity and targets the RAF/MEK/ERK pathway and receptor tyrosine kinases involved in tumor progression and angiogenesis. Cancer Res 2004, 64:7099-7109.

16. Xi M, Zhang L, Zhao L, Li QQ, Guo SP, Feng ZZ, Deng XW, Huang XY, Liu MZ: Effectiveness of stereotactic body radiotherapy for hepatocellular carcinoma with portal vein and/or inferior vena cava tumor thrombosis. PLoS One 2013, 8:e63864.

17. Tanaka Y, Nakazawa T, Komori S, Hidaka H, Okuwaki Y, Takada J, Watanabe M, Shibuya A, Minamino T, Yamamoto H, Kokubu S, Hayakawa K, Koizumi W: Radiotherapy for patients with unresectable advanced hepatocellular carcinoma with invasion to intrahepatic large vessels: efficacy and outcomes. J Gastroenterol Hepatol 2014, 29:352-357.

18. Murakami E, Aikata H, Miyaki D, Nagaoki Y, Katamura Y, Kawaoka T, Takaki S, Hiramatsu A, Waki K, Takahashi S, Kimura T, Kenjo M, Nagata Y, Ishikawa M, Kakizawa H, Awai K, Chayama K: Hepatic arterial infusion chemotherapy using 5-fluorouracil and systemic interferon-a for advanced hepatocellular carcinoma in combination with or without three-dimensional conformal radiotherapy to venous tumor thrombosis in hepatic vein or inferior vena cava. Hepatol Res 2012, 42:442-453.
19. Eisenhauer EA, Therasse P, Bogaerts J, Schwartz LH, Sargent D, Ford R, Dancey J, Arbuck S, Gwyther S, Mooney M, Rubinstein L, Shankar L, Dodd L, Kaplan R, Lacombe D, Verweij J: New response evaluation criteria in solid tumors: revised RECIST guideline (version 1.1). Eur J Cancer 2009, 45:228-247.

20. Lencioni R, Llovet JM: Modified RECIST (mRECIST) assessment for hepatocellular carcinoma. Semin Liver Dis 2010, 30:52-60.

21. Oken MM, Creech RH, Tormey DC, Horton J, Davis TE, McFadden ET, Carbone PP: Toxicity and response criteria of the Eastern cooperative oncology group. Am J Clin Oncol 1982, 5:649-655.

22. Guo S, Fraser MW: Propensity Score Analysis: Statistical Methods and Applications. Advanced Quantitative Techniques in the Social Sciences Series; v. 12. Los Angeles: SAGE Publications, Inc; 2010.

23. Pirisi M, Avellini C, Fabris C, Scott C, Bardus P, Soardo G, Beltrami CA, Bartoli E: Portal vein thrombosis in hepatocellular carcinoma: age and sex distribution in an autopsy study. J Cancer Res Clin Oncol 1998, 124:397-400.

24. Choi GH, Shim JH, Kim MJ, Ryu MH, Ryoo BY, Kang YK, Shin YM, Kim KM, Lim YS, Lee HC: Sorafenib alone versus sorafenib combined with transarterial chemoembolization for advanced-stage hepatocellular carcinoma: results of propensity score analyses. Radiology 2013, 269:603-611.

25. Yamamoto K, Imamura H, Matsuyama Y, Kume $Y$, Ikeda H, Norman GL, Shums Z, Aoki T, Hasegawa K, Beck Y, Sugawara Y, Kokudo N: AFP, AFP-L3, $D C P$, and GP73 as markers for monitoring treatment response and recurrence and as surrogate markers of clinicopathological variables of HCC. J Gastroenterol 2010, 45:1272-1282.

26. Liu L, Zhao Y, Qi X, Cai G, He C, Guo W, Yin Z, Chen H, Chen X, Fan D, Han $\mathrm{G}$ : Transjugular intrahepatic portosystemic shunt for symptomatic portal hypertension in hepatocellular carcinoma with portal vein tumor thrombosis. Hepatol Res 2013, doi:10.1111/hepr.12162. [Epub ahead of print].

27. Hidaka H, Nakazawa T, Kaneko T, Minamino T, Takada J, Tanaka Y, Okuwaki Y, Watanabe M, Shibuya A, Koizumi W: Portal hemodynamic effects of sorafenib in patients with advanced hepatocellular carcinoma: a prospective cohort study. J Gastroenterol 2012, 47:1030-1035.

28. Coriat R, Gouya H, Mir O, Ropert S, Vignaux O, Chaussade S, Sogni P, Pol S, Blanchet B, Legmann P, Goldwasser F: Reversible decrease of portal venous flow in cirrhotic patients: a positive side effect of sorafenib. PLOS One 2011, 6:e16978.

\section{doi:10.1186/1471-230X-14-84}

Cite this article as: Nakazawa et al:: Overall survival in response to sorafenib versus radiotherapy in unresectable hepatocellular carcinoma with major portal vein tumor thrombosis: propensity score analysis. BMC Gastroenterology 2014 14:84

\section{Submit your next manuscript to BioMed Central and take full advantage of:}

- Convenient online submission

- Thorough peer review

- No space constraints or color figure charges

- Immediate publication on acceptance

- Inclusion in PubMed, CAS, Scopus and Google Scholar

- Research which is freely available for redistribution 